\title{
A Comparative Study on the Performance of Direct Carbon Solid Oxide Fuel Cell Powered with Different Rank Coals
}

\author{
Guoyang Liu*, Yating Zhang, Anning Zhou*, Junzhe Wang, Jiangtao Cai, Yongqiang \\ Dang
}

College of chemistry and chemical engineering, Xi'an University of Science and

Technology, Xi'an, 710054, China;

\section{Supporting Information:}

According to the Chinese standard (GB/T 7560-2001), acid-washing was conducted to remove inorganic minerals contained in the coal samples. The detailed operating conditions of the demineralizing process is as follows: a $6 \mathrm{~g}$ coal sample was leached with $40 \mathrm{~mL}$ of a $5 \mathrm{M} \mathrm{HCl}$ solution and stirred continuously at $50^{\circ} \mathrm{C}$ for 50 minutes in a polyethylene beaker, and then filter. The residue was added to $40 \mathrm{~mL}$ of $45 \mathrm{wt} \% \mathrm{HF}$ solution, and stirred continuously at $50{ }^{\circ} \mathrm{C}$ for 50 minutes, after which the residue was obtained by filtration. The residue from the HF leaching stage was leached again with $40 \mathrm{~mL}$ of $5 \mathrm{M} \mathrm{HCl}$ using a step similar to the initial step. Each time the resulting filter residue was washed several times with $70{ }^{\circ} \mathrm{C}$ of distilled water to neutral. The remaining acid-treated coal samples were dried in a vacuum oven at $80^{\circ} \mathrm{C}$.

Fig. S1 is a scanning electron microscopic image of three kinds of coal and corresponding semi-coke. From Fig S1, it can be seen that the surface of TX coal is relatively smooth and the corresponding semi-coke surface is relatively smooth; while the surface of DHS coal is rough, with many small lamellar structures piled up, and the surface of semi-coke obtained by pyrolysis is very rough; while the surface of HLH coal has more lamellar structures, and irregular pore structure is formed on the surface of semi-coke after pyrolysis. The surface morphology and pore structure of semi-coke reflect the difference of reactivity. 

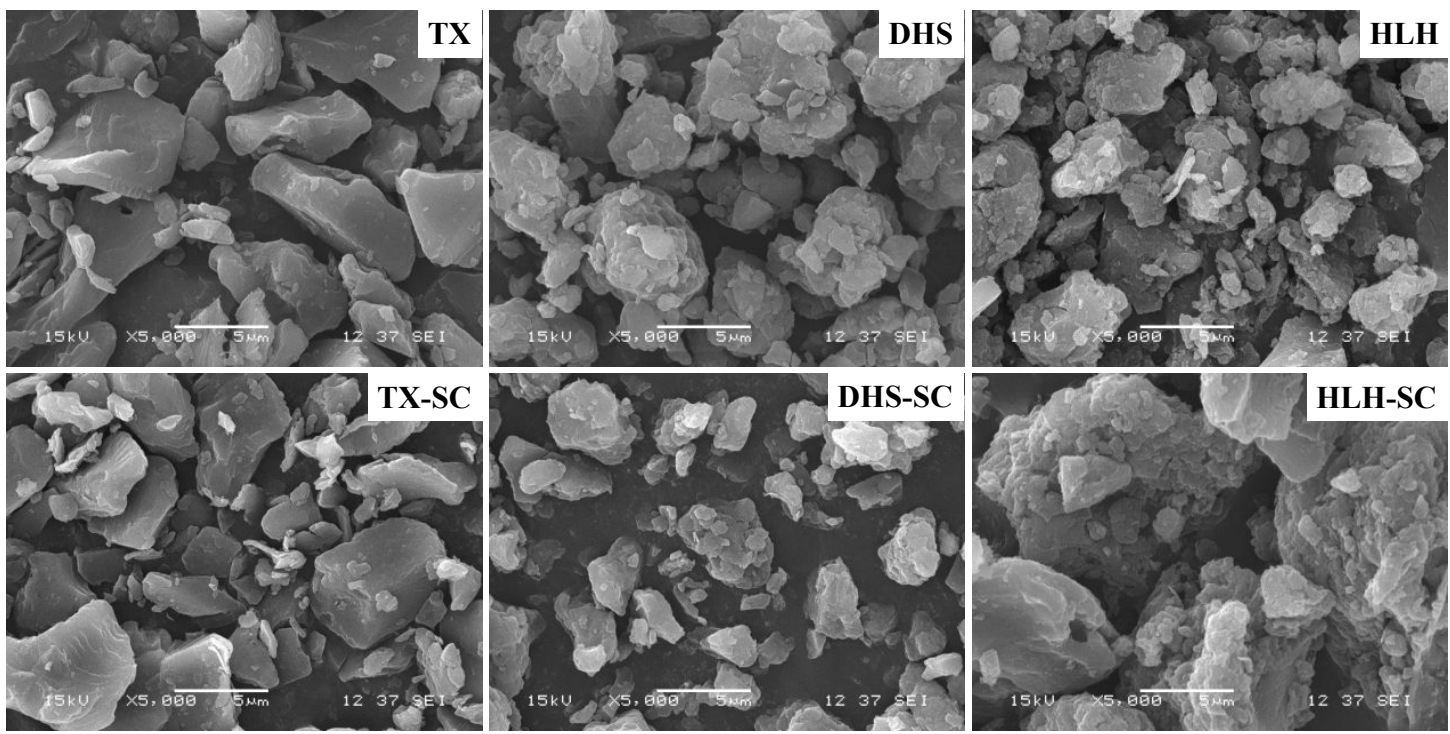

Fig. S1. SEM of raw coals and semi-cokes

In order to investigate the effect of metal elements in ash on the electrochemical reaction of solid carbon, some metal elements in ash were added to solid carbon fuels of DCFC with by equal volume impregnation method respectively. Fig. S2 shows the effect of different metal elements on the performance of DCFC. It can be seen that $\mathrm{K}, \mathrm{Na}, \mathrm{Ca}, \mathrm{Ni}$ and $\mathrm{Fe}$ metal elements can increase the open-circuit voltage (Fig. S2(a)) and the maximum power density (Fig. S2(b)) of DCFC, which reveals that these metal elements can improve the electrochemical reactivity of solid carbon. However, Mg and Al metal elements reduce the open-circuit voltage of DCFC, which reveals that $\mathrm{Mg}$ and $\mathrm{Al}$ metal elements passivate the reactivity of solid carbon.
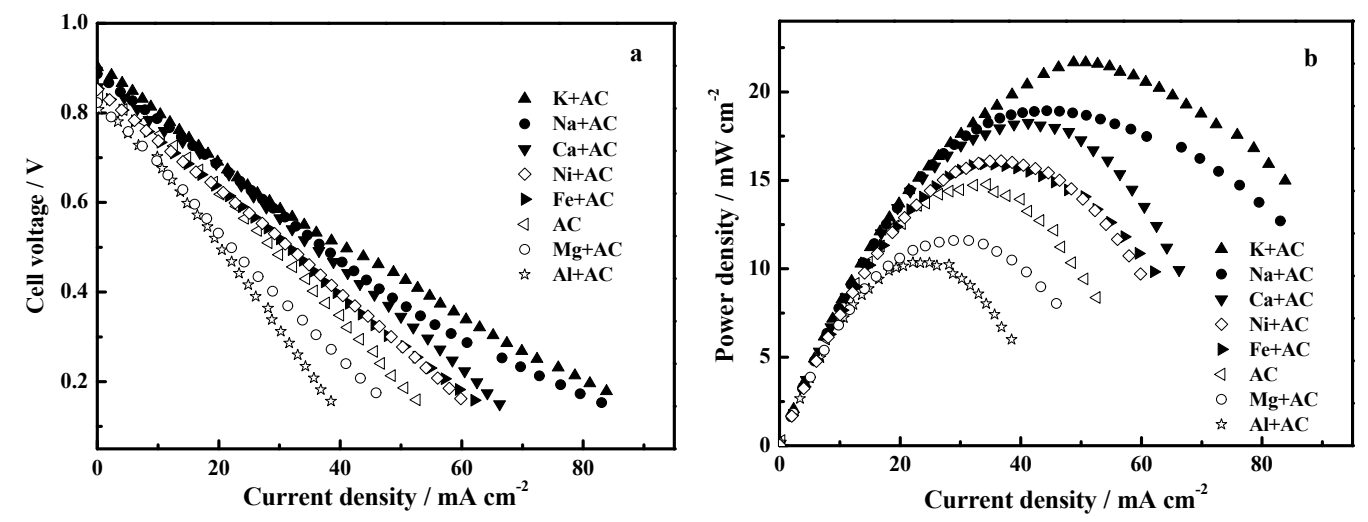

Fig. S2. Effect of metal elements on performance of DCFC

The ash composition of coal samples is measured as shown in Table S1. It is obvious from Table $\mathrm{S} 1$ that the ash of three types of coal contains a large amount of $\mathrm{SiO}_{2}$ which can not promote the performance of DCFC, but can inhibit the anodic reaction of DCFC. This is why the ash content of the three types of coal hinders the performance of DCFC with raw as fuel.

Table S1. Determination of ash composition of coal samples

\begin{tabular}{llllllllll}
\hline Composition & $\mathrm{CaO}$ & $\mathrm{Fe}_{2} \mathrm{O}_{3}$ & $\mathrm{~K}_{2} \mathrm{O}$ & $\mathrm{MgO}$ & $\mathrm{Na}_{2} \mathrm{O}$ & $\mathrm{SiO}_{2}$ & $\mathrm{Al}_{2} \mathrm{O}_{3}$ & $\mathrm{NiO}$ \\
\hline
\end{tabular}




\begin{tabular}{ccccccccc}
\hline$/ \mathrm{wt} \%$ & & & & & & & \\
\hline TX & 8.241 & 21.251 & 5.283 & 0.046 & 0.150 & 47.632 & 27.394 & 0.003 \\
DHS & 6.566 & 25.135 & 2.727 & 0.067 & 0.037 & 44.577 & 20.887 & 0.004 \\
HLH & 16.679 & 9.522 & 6.822 & 0.074 & 0.074 & 51.744 & 15.081 & 0.004 \\
\hline
\end{tabular}

The crystallite parameters of the semi-coke samples were estimated from the Bragg and Scherrer equations:

$$
\begin{aligned}
& d_{002}=\frac{\lambda}{2 \sin \left(\theta_{002}\right)} \\
& L=\frac{K \lambda}{\beta \cos \theta}
\end{aligned}
$$

where $\lambda$ represents the X-ray wavelength $(0.15406 \mathrm{~nm}), \theta_{002}$ the diffraction angle of the (002) peak, $\mathrm{d}_{002}$ the interlayer spacing of the carbon crystallite structure, $\mathrm{K}$ (shape factor) is 0.89 for $\mathrm{L}_{\mathrm{c}}$ and 1.84 for $L_{a}, \beta$ represents the peak width at the half-maximum intensity of the diffraction peak, $\mathrm{L}_{\mathrm{c}}$ the crystalline size perpendicular to the basal plane based on the (002) reflection, and La the crystalline size parallel to the basal plane based on the (100) reflection. All of the calculated values of the parameters for the carbon crystallite structure are listed in Table S2.

Table S2. Crystalline parameters of the semi-cokes from three coal samples.

\begin{tabular}{cccc}
\hline samples & $\mathrm{d}_{002} / \mathrm{nm}$ & $\mathrm{L}_{\mathrm{c}} / \mathrm{nm}$ & $\mathrm{L}_{\mathrm{a}} / \mathrm{nm}$ \\
\hline TX-SC & 0.366 & 1.233 & 4.425 \\
DHS-SC & 0.368 & 1.029 & 5.935 \\
HLH-SC & 0.375 & 0.902 & 2.440 \\
\hline
\end{tabular}

The relative concentrations of the functional groups of semi-cokes corresponding to each peak can be obtained by employing the ratio of each characteristic peak area within the total peak area, the results of which are displayed in Table $\mathrm{S} 3$.

Table S3. Summary XPS analysis of the C1s in the semi-cokes.

\begin{tabular}{ccccc}
\hline Position/eV & TX-SC/\% & DHS-SC/\% & HLH-SC $\%$ & Attribution \\
\hline 284.6 & 45.81 & 4.8 & 1.91 & $\mathrm{C}=\mathrm{C}$ \\
285.6 & 40.67 & 27.05 & 27.02 & C-C or C-H \\
286.3 & 1.38 & 49.15 & 47.82 & C-O \\
287.2 & 5.6 & 11.68 & 14.58 & C=O \\
289.2 & 6.54 & 7.32 & 8.67 & O-C=O \\
\hline
\end{tabular}

The specific surface area and pore-size distribution of samples were calculated from nitrogen adsorption isotherm data using the BET and BJH methods, respectively. The detailed pore parameters of semi-cokes are also summarized in Table S4.

Table S4. Textural properties of samples after pylorysis at $850^{\circ} \mathrm{C}$.

\begin{tabular}{llll}
\hline Sample & BET surface & Pore volume $/ \mathrm{cm}^{3} \cdot \mathrm{g}^{-1}$ & Average pore \\
\hline
\end{tabular}




\begin{tabular}{cccc}
\hline & area $/ \mathrm{m}^{2} \cdot \mathrm{g}^{-1}$ & & size $/ \mathrm{nm}$ \\
\hline TX-SC & 15.834 & 0.021 & 4.323 \\
DHS-SC & 63.731 & 0.096 & 3.416 \\
HLH-SC & 320.487 & 0.224 & 3.733 \\
\hline
\end{tabular}

Select EIS data was modelled using ZView TM software (Scribner Associates, Inc., USA) using equivalent circuits consisting of a serial resistance $\mathrm{R}_{0}$, and two arcs to describe the polarization resistance. In the high-frequency region, the intersection of the impedance spectra with the real axis represents the ohmic resistance $\left(\mathrm{R}_{\mathrm{o}}\right)$ of the DCFC, whereas the intersection in the low-frequency region represents the total resistance $\left(\mathrm{R}_{\mathrm{T}}\right)$ of the DCFC. The polarization resistance $\left(\mathrm{R}_{\mathrm{P}}\right)$ is obtained by subtracting the ohmic resistance from the total resistance. The obtained parameters from the equivalent circuit fitting are summarized in Table S5.

Table S5. The resistance parameters of the DCFC with different fuels.

\begin{tabular}{ccccccccc}
\hline Resistance $/ \Omega \mathrm{cm}^{2}$ & $\mathrm{TX}$ & DHS & HLH & D-TX & D-DHS & D-HLH & CO & Graphite \\
\hline $\mathrm{R}_{\mathrm{O}}$ & 1.715 & 2.021 & 2.262 & 2.111 & 1.557 & 2.114 & 1.443 & 1.647 \\
$\mathrm{R}_{\mathrm{P}}$ & 4.582 & 10.298 & 13.368 & 19.630 & 8.571 & 6.655 & 4.958 & 31.545 \\
$\mathrm{R}_{\mathrm{T}}$ & 6.297 & 12.319 & 18.630 & 21.741 & 10.128 & 8.769 & 6.401 & 33.192 \\
\hline
\end{tabular}

